\title{
Improvement of Rice Breeding for Salinity Tolerance
}

\author{
Dejen Bekis \\ Ethiopian Institute of Agricultural Research, Fogera National Rice Research and Training Center, \\ South Gondar, Ethiopia
}

\begin{abstract}
Rice is one of the most significant food crop of the world. The production of rice is the second-highest in the world. Salinity is a serious constraint to increase rice production worldwide. Review of recent efforts achieved towards rice breeding for salinity tolerance has a paramount importance beside for rice production improvement in Ethiopia. Rice is a relatively new crop to Ethiopia; however, the crop is relatively well adapted to different parts of the country. Salinity is a problem of many irrigated, arid and semi-arid areas of the world where rain fall is insufficient to leach out salts from the root zone. Typical symptoms of salt injury in rice are stunted growth, leaf rolling, white leaf tip, white blotches in the leaf blade, drying of the older leaves and poor root growth. The main mechanisms of salt tolerance are control of salt uptake, reducing damage under excessive ion uptake and osmotic adjustment. The three major breeding approaches for salinity tolerant varietal development are conventional breeding, marker assisted selection and genetic engineering. Conventional rice breeding approaches exercised for thousands of years. But, the progress is slow, due to the time consuming process, the quantitative nature of most agronomic traits make difficulties in genotypes selection. However, modern breeding is more precise and efficient and easily identify undesirable genes that can be eliminated in future generations. In rice, markers like RAPDs, AFLPs, ISSRs and SSRs have been used. Among these DNA markers, SSRs is highly preferable for gene tagging and mapping efforts. The development of salt-tolerant variety by transgenic way needs more investigation. To date, transgenic salt tolerant variety has not yet reached at farmers' field. In Ethiopia a little beat was done to identify rice genotypes adaptable to adverse saline soil conditions. From here on, more research findings highly crucial for the development of salinity tolerant rice varieties in the country. Therefore, it is a good opportunity for rice breeders to develop salt tolerant high yielding varieties in Ethiopia.
\end{abstract}

Keywords: Conventional breeding, Genetic engineering, Marker-assisted selection, Rice, Salt tolerance

DOI: $10.7176 / \mathrm{JEES} / 10-5-02$

Publication date:May $31^{\text {st }} 2020$

\section{Introduction}

Rice (Oryza sativa L.) belongs to the grass family Poaceae and one of the most consumed staple foods around the world, especially in Asia. The production of rice grain is the second-highest in the world, next to wheat (FAO, 2013). Historically, rice was cultivated 10000 years ago in the river valleys of South and Southeast Asia and China since it served as the most important food for people. Although Asia is the main place of rice cultivation but it also harvested in other continents like Latin America, Europe, USA and some parts of Africa(Zibaee, 2013).

It is introduced to Ethiopia in 1970 s and fastly distributed within the country due to the presence of vast suitable agro ecologies for rice production in the country (Beakaletal, 2016). 35 rice varieties were developed for different rice ecosystems in Ethiopia. Due to emphasis for promotion of agricultural production that rice is considered as the "Millennium Crop"(MOARD, 2010).

There are only two major species of rice cultivated in the world i.eOryza sativa or Asian rice and Oryzaglaberrimaor African rice. The rice varieties grown across the world belongs overwhelmingly to the $O$. Sativa (O.S) species, while cultivation of the O.G is confined to Africa. O.G varieties are fast being replaced by the O.S due to greater in yield.However; O.G has a special advantage afford by its stress resistance and fast maturing growth. In the late 1990s, the Africa Rice Centre, WARDA, managed to cross the two species into an inter-species hybrid called "NERICA" (standing for "New Rice for Africa"), which combines the ruggedness of local African rice with the high productivity of the Asia rice (Calpe, 2006). Rice ecosystems based on International Rice Research Institute (IRRI) classification, rice is cultivated in four broad production ecosystems (Irrigated, rain fed lowland, upland and flood-prone) (Calpe, 2006). Most cultivated rice is grown in flooded fields and rain fed low lands. But, there are some constraints on the production of this economical crop in the world because of biotic and a biotic stresses.

Among these; salinity is the second most widespread soil problem in rice growing countries next to drought which considers as a serious constraint to increase rice production worldwide. Salt affected soils have very low productivity because of dominance of the soluble salts (salinity) and /or exchangeable Na+ ions. Salinity affects $7 \%$ of the world's land area, which accounted to 930 million hectares. Currently, an estimated area of 150 million ha of potential rice land in the tropics and subtropics is affected by salinity (Akbar and Ponnamperuma, 1982).In Ethiopia, previous reports indicated that more than 11 millon ha of arable land has been affected by salinity and it is the first in Africa (Dawitand Hussien,2017). 
Thus, there is an urgent need to develop varieties, not only withstand high levels of salt but can also maintain optimum yield levels(Khatun et al., 1995; Zeng et al., 2001).To minimize the effect of salinity stress on rice, a number of strategies have been employed. Recently, crop improvement strategies based on the use of molecular marker techniques and biotechnology have been used in conjunction with traditional breeding to develop salt tolerant crops (Miller et al., 2010). Availability of the genome sequence of rice is proving to be an additional benefit to look for the suitable target genes that can be employed for selected gene manipulation to achieve tolerance against various abiotic stresses in rice (In the recent past, genome-wide analysis of an array of protein families has given insight into the architecture of various genes as well as their responsiveness towards various environmental abuses (Goff et al., 2002). Therefore, it is crucial to review and understand recent efforts achieved towards rice breeding for salinity tolerance beside for rice production improvement in the country in one way or another accordingly.

\section{Importance of Rice}

Rice farming is the largest single use of land for food. Rice field covers $11 \%$ of arable land. It is the most important economic activity of earth. World rice production is spread across at least 114 countries (FAO, 2013). Rice is grown in 250 million Asian farms, more than for any other crop. These, provides livelihoods not only for the millions of small-scale farmers and their families but also for the many landless workers who derive income from working on these farms (Mohanty, 2013). Rice has shaped the culture, diets and economic of millions people. For more than half of the humanity "rice is life". Rice is the main source of energy and protein. It can contribute significant nutritional amounts of thiamin, riboflavin, niacin, and zinc to the diet. The non-food rice parts are also used us for different purposes. Rice straw is used as animal feed, fuel source, paper manufacturing and in cottage industry for preparation of hats, mats and ropes. Considering its importance position, the United Nation designated year 2004 as the "International Year of rice (ABSF, 2010).

In Sub-Saharan Africa (SSA), consumption is increasing at a rate of $6 \%$ per annum, the highest in the world. The rate of increase in the consumption of rice in Africa has not been matched by corresponding increases in production and the demand-supply gap.The continent currently imports about US \$5 billion worth of rice every year. Imported rice accounts for about 40\% of Sub-Saharan Africa local rice consumption (Akinwale et al., 2011; Mulugeta et al., 2012). Rice is a relatively new crop to Ethiopia; however, the crop is relatively well adapted to different parts of the country. Recently, demand of rice production is increasing in alarming rate that more than 300,000 tons introduced year after year for consumption. Rice is among the target commodities that have received due emphasis, considered as the 'millennium crop' in contributing to food and nutritional security, income generation, poverty alleviation and socio-economic development of Ethiopia.

\section{Effects of soil salinity and plant response}

Salinity is a problem of many irrigated, arid and semi-arid areas of the world where rain fall is insufficient to leach out salts from the root zone. Saline soils defined as those that contain sufficient salt in the root zone affecting the growth of plants (Ponnamperuma, 19994). FAO (1997) defined saline soil as on that has greater than EC of saturation $4 \mathrm{ds} / \mathrm{m}$ and soils exceeding ESP $15 \%$. It is one of the major obstacles to increase production in rice growing areas worldwide. The reduction in growth and yield starts at 3 and $4 \mathrm{ds} / \mathrm{m} \mathrm{NaCl}$ in salt sensitive and salt tolerance in rice respectively (Aslam et al.,1993). Whereas, severe injuries reported in range of EC of 8-10 ds $/ \mathrm{m}$. Rice is rated as an especially salt-sensitive crop (Shannon et al., 1998). Saline soils are classified based on electrical conductivity (EC) of the soil solution which detects osmotic problems and exchangeable sodium percentage (ESP) indicative of a physical dispersion problem.

Salt affected soils are classified as: non saline/non-sodic soils (ESP $\leq 15 \%$; EC $\leq 4 \mathrm{mmhos} \mathrm{cm}-1$ ); saline soil $(\mathrm{ESP} \leq 15 \%$; EC $>4 \mathrm{mmhos} \mathrm{cm}-1)$; sodic soil (ESP $>15 \%$; EC $\leq 4 \mathrm{mmhos} \mathrm{cm}-1)$ and saline sodic soil (ESP $>15 \%$; $\left.\mathrm{EC}>4 \mathrm{mmhos} \mathrm{cm}^{-1}\right)$. The $\mathrm{pH}$ of saline soils is generally less than 8.5 , of saline sodic soils about 8.5 and of sodic soils more than 8.5 (USDA, 1954).According to the FAO, 2001 salinity may be classified into five levels(Table 1).

Table 1.Indicative soil salinity classes and implications for crop performance

\begin{tabular}{|l|l|l|l|}
\hline \hline EC at $25^{\circ} \mathbf{C}$ & \multicolumn{2}{|l|}{ Salt Concentration } & Effect on crops \\
\hline$\left.(\mathrm{dS} \mathrm{m})^{-1}\right)$ & $\left(\mathrm{cmol} \mathrm{l}^{-1}\right)$ & $(\%)$ & \\
\hline$<2.0$ & $<2$ & & mostly negligible \\
\hline $2.0-4.0$ & $2-4$ & $<0.15$ & some damage to sensitive crops \\
\hline $4.0-8.0$ & $4-8$ & $0.15-0.35$ & serious damage to most crops \\
\hline $8.0-15.0$ & $8-15$ & $0.35-0.65$ & only tolerant crops succeed \\
\hline$>15$ & $>15$ & $>0.65$ & few crops survive \\
\hline
\end{tabular}

EC: Electric conductivity(Adapted from FAO, 2001)

Low salinity at the early developmental stages can have a stimulatory effect on plant growth. However, high salinity levels at any growth stage will inhibit the growth and yield of rice (Khatun and Flowers, 1995). High 
salinity is detrimental to rice growth as it causes:

1. Nutritional disorders by decreasing the uptake of cations, such as potassium and calcium, but also of anions such as phosphorus and nitrate

2. Ion cytotoxicity mainly due to elevated concentrations of $\mathrm{Na}^{+}, \mathrm{Cl}^{-}, \mathrm{SO} 4$-and

3. Osmotic stress (Zhu, 2001).

Typical symptoms of salt injury in rice are stunted growth, leaf rolling, white leaf tip, white blotches in the leaf blade, drying of the older leaves, and poor root growth (Castillo et al., 2003).
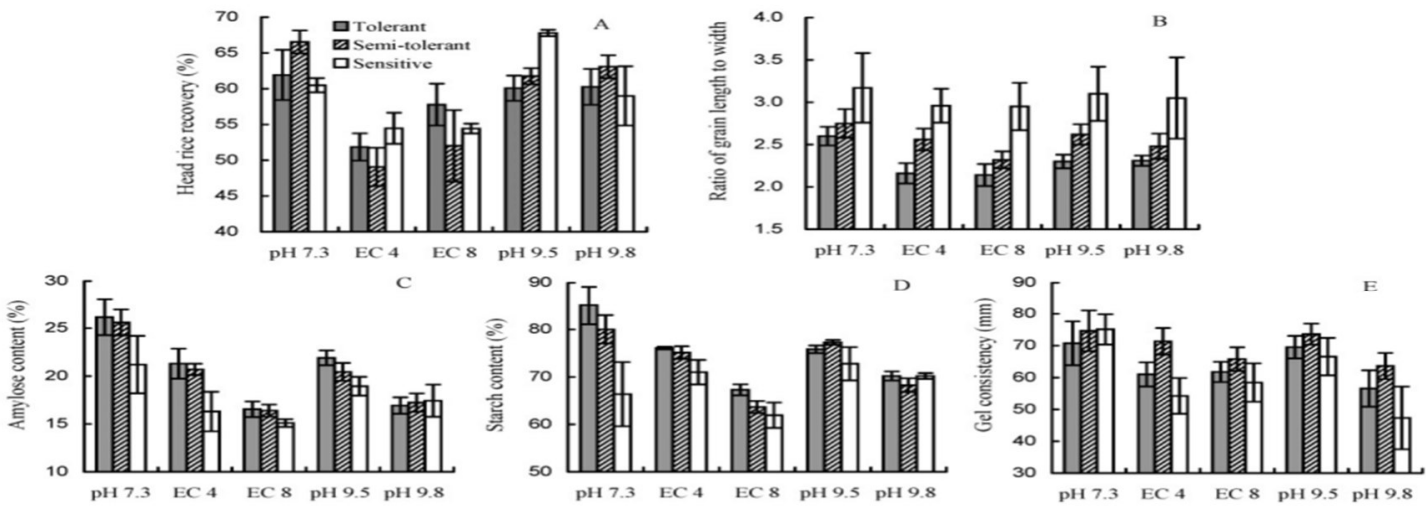

1. Effects of soil salinity (EC) and alkalinity $(\mathrm{pH})$ levels on an average head rice recovery (A), ratio of grain length to width (B), amylose content (C), starch content (D) and gel consistency (E) of tolerant, semi-tolerant and sensitive rice genotypes. rror bar repres

Fig.1. Effect of soil salinity (EC) and alkalinity (pH)

\section{The Mechanism of salt tolerance}

Salt tolerance defined as the capacity of the plant to cope with the adverse effects of excess salt in the rooting medium. This indicates that a plant can withstand a precise amount of salt without adverse effects. Salttolerance of a plant depends on salt concentration, condition of crop growing, age and varieties of crops. If salt tolerance is defined in terms of reduction in growth or yield caused by specific concentration of salt that meaning given for the farmers. Differences in salt tolerance exist between species and between genotypes within a species.

Thus, rice is tolerant during germination, can become highly sensitive during the early seedling stage. Cultivars with a high level of salt tolerance during the vegetative growth can become temporarily salt-sensitive during pollination and fertilization before again increasing the tolerance level at maturity. Salinity during the reproductive stage depresses grain yield much more than salinity during the vegetative growth stage.

There are two essential parameters sufficient for expressing salt tolerance in rice. Threshold is the maximum allowable salinity without yield reduction and whereas slope is the percent of yield reduction per unit increase in salinity beyond the threshold. The threshold and slope of rice (Oryza sativa) are $3.0 \mathrm{dsm}^{-1}$ and $12 \%$ per dsm ${ }^{-1}$ of saturated soil extract (ECe) respectively (Mass and Hoffman, 1977). The main mechanisms of salt tolerance are control of salt uptake, reducing damage under excessive ion uptake and osmotic adjustment.

Control of salt uptake: under conditions of low salinity, tolerance in a plant can be due to minimize salt up take(exclusion) and which is achieved through selectivity of carrier across roots into xylem by better water use efficiency minimizing dilution of salt concentration in the plant.

Reducing damage under excessive ion uptake: accommodate salt load without reducing leaf photosynthesis activity, removal of excess salt from leaf to specialized structures, salt gland s and hairs

Osmotic adjustment: under high salinity, osmotic adjustment to external water potential is required those are better nutrient acquision and high ion selectively; synthesize organic solutes to adjust the osmotic potential of the cytoplasm and vacuole and compartmentalization of salt ions in the vacuoles.

\section{Breeding approaches for salinity tolerance in rice}

To minimize the effect of salinity stress on rice, a number of strategies have been employed. More recently, crop improvement strategies that are based on the use of molecular marker techniques and biotechnology are being used in conjunction with traditional breeding efforts to develop salt tolerant crop species. Based on the known mechanisms that rice has to cope with salinity stress, the three major approaches next to primary activities for varietal development are conventional breeding, marker assisted selection and genetic engineering (Miller et al., 2010).

\subsection{Prerequisite for the development of salt tolerant cultivars}

Existence of genetic variability for salt tolerance within species is of paramount importance in crop improvement program. Hence, choice ofgermplasm in breeding program is most crucial as the success lies on it. Extensive 
germplasm collection provides a useful source of genetic diversity for the studied traits. Before designing any ideal plant type, it is essential to define the soil and agro climatic conditions of the target areas for which they are to be developed. Genotypes which are suitable for coastal areas may or may not be fit for sodic soils or inland saline soils and vice-versa. Therefore, exact site characterization is an important aspect to meet the objective of salt resistant cultivar development.

Ideally germplasm should differ as much as possible for the traits to be improved or introgressed. Other traits should not vary too much otherwise keeping all the desirable traits into one superior agronomic background become very difficult. Reliable and repeatable screening techniques are the mainstay of any successful breeding program specifically for biotic or abiotic stress breeding. Degree of salt stress can affect the different crops differently. For rice, soil salinity beyond ECe $\sim 4 \mathrm{dS} / \mathrm{m}$ is considered moderate salinity while more than $8 \mathrm{dS} / \mathrm{m}$ becomes high. Similarly pH $8.8-9.2$ is considered as non-stress while9.3 - 9.7 as moderate stress and $\geq 9.8$ as higher stress. Extremely high salt stress conditions kills the plant but the moderate to low salt stress affect the plant growth rate and thereby manifest symptoms which could be associated with morphological, physiological or biochemical alterations.

Most of the morphological parameters like low tillering, spikelet sterility, less florets per panicle, low 1000 grain weight and leaf scorching are affected uniformly under both sodicity and salinity. It is observed that crop varieties and breeding lines do differ for their inherent capability to modify various physiological and biochemical processes in response to the salt stress. Though numerous physiological and biochemical changes take place under altered stress environment but only few of them change very significantly and also contribute a lot to the salt tolerance mechanism. These changes control the solute and water balance and their distribution on whole plant and tissue basis. Physiological and biochemical manifestations under higher salt stress conditions are high $\mathrm{Na}^{+}$ transport to shoot, preferential accumulation of $\mathrm{Na}$ in older leaves, high $\mathrm{Cl}$ uptake, lower $\mathrm{K}^{+}$uptake, lower fresh and dry weight of shoot and roots, low $\mathrm{P}$ and $\mathrm{Zn}$ uptake change in esterase isozyme pattern, increase of non-toxic organic compatible solutes and increase in Polyamine levels.

Parameters that should be considered for screening are morphological, survival of the plant, injury score, phenotypic expression, grain yield, stability of traits over environments; mean tolerance index, physiological, tissue tolerance and $\mathrm{Na} / \mathrm{K}$ ratio.

\subsubsection{Morphological parameters}

Though there is no single definite morphological marker available for salt tolerance or sensitivity in any crop, a combination of criteria give a good indication towards the salt response of crop plants. Therefore, several parameters are used in combination for the effective and reproducible screening.

Germination studies: Germination percentage, coleoptile and radicle length under varying degree of salt stress for different crops is a good salt tolerance indicator at initial stages. Higher salt concentration delays or reduces the germination.

Survival of the plant: It is mainly limited to the seedling studies; however, in some of the adult plant studies it has also been considered. Under moderate stress, plant survival is not a problem but under higher stress, it is a good selection criterion.

Injury score: Individual plant or group of genotypes are scored usually on 1 to 5 or 1 to 9 scale where lower score towards 1 states tolerant and higher score denotes sensitive genotypes.

Phenotypic expression: Excessive tip burning especially in younger leaves, spikelet sterility and stunted growth are considered for the overall phenotypic expression of the genotype under stress environment.

Grain Yield: In the absence of any simple and reliable selection criteria, the $50 \%$ reduction in grain yield of the genotypes under salt stress in relation to the normal (non-stress) yield has been considered as critical limit for selection/rejection of the genotypes.

Stability of traits over environments: The genotype with high mean, near to unit regression value (bi) and uniformity of regression under multiple stress environments are judgedas suitable, stable and adaptable genotypes for sustainable productivity in problem soils. Selection for high mean yield is a fundamental selection criterion for all the varieties while selection based on unit regression value and least deviation from regression indicates the stable performance across a range of environments (Singh and Mishra, 1997).

Mean tolerance index (MTI): It is a product of Stress Resistance Index (SRI) and Response Index (RI) of the genotype. Here SRI is the performance of a genotype for that trait averaged over all the stress environment in conjunction with performance under corresponding non-stress environment and RI is the mean of the genotype for the trait under all stress environments divided by the mean performance of all the genotypes over all the stress locations (Sinha, 1997).

\subsubsection{Physiological parameters}

Extremely high salt concentration kills the plant but the moderate salt stress exhibits the growth differences among the crop varieties. Tolerance to salt stresses is a complex phenomenon because it may require the combination of different independent and/or interdependent mechanisms and pathways.

Na and K uptake: In general, tolerance of a crop variety was found to be associated with its ability to restrict 
potentially toxic ion uptake like $\mathrm{Na}^{+}$and associated with preferential uptake of the balancing ion like $\mathrm{K}^{+}$. There are larger differences in ion $\left(\mathrm{Na}^{+}\right.$and $\left.\mathrm{K}^{+}\right)$uptake between the species in comparison to the genotypic differences within a crop species.

Tissue tolerance: Tissue tolerance is measured in terms of LC50which is an analogue of LD50. Here LC50is the concentration of sodium (in mmolg-1 ethanol-insoluble dry wt.) in the leaf tissue which causes a $50 \%$ loss of chlorophyll. It is taken as an indicator of metabolic damage to the tissue due to the salt load. LC50 values differ for different genotypes and all varieties in high tissue tolerant category were not highly salinity tolerant and viceversa (Mishra et al., 1992).

\subsection{Conventional Breeding Approaches}

Almost all the conventional breeding methods have been followed for the development of the salt tolerant materials i.e. introduction, selection, hybridization, mutation and shuttle breeding approach. Later on other salt tolerant varietal series were developed through recombination breeding methods like pedigree method, modified bulk pedigree method and shuttle breeding. The segregating materials are put in the long rows under salt stress with space planting in F2 particularly. Selection pressure is gradually increased with the generation advancement simultaneously in moderate stress and high stress of sodicity and salinity.

The major aim of rice breeding program is to integrate the desired agronomic characteristics with an increasing level of tolerance to salinity. Native varietal tolerance has long been exploited to characterize the difference between salt-sensitive and salt tolerant cultivars (Winicov, 1998). By selecting individual physiological traits contributing to salt tolerance and combining them in breeding programs could make possible to increase resistance to salt beyond the existing phenotypic range (Khatunetal.,1995). Due to these efforts, considerable success has been obtained in raising rice genotypes with improved tolerance towards salinity (Das et al., 2000). Conventional breeding techniques viz.,interspecific hybridization, screening and recurrent selection have been made (Zhenget al., 2003). Select phenotypically when plant height, panicle length, tiller number, spikelet number and greater yield than those of the original variety.
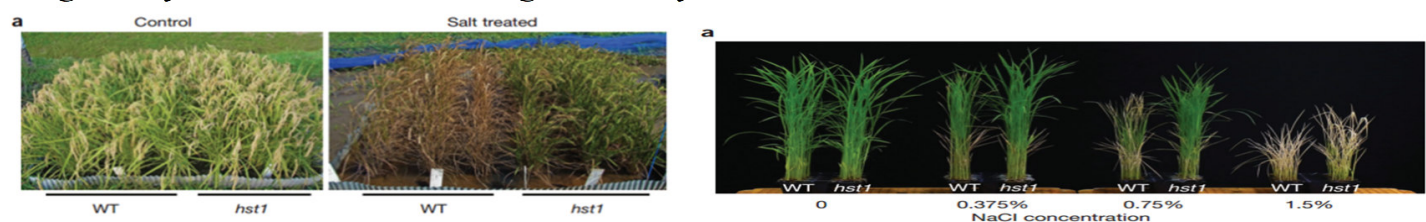

Fig.2. Salinity tolerance level on the phenotype of WT and hst1 under controlled and salt treated condition

\subsection{Marker Assisted Selection (MAS)}

Genetic marker isthe biological features which determined by allelic forms of genes or genetic loci and can be transmitted from one generation to another. Thus, it can be used as experimental probes or tags to keep track of an individual, a tissue, a cell, a nucleus, a chromosome or a gene. Genetic markers used in genetics and plant breeding include morphological markers, biochemical markers (alloenzymes and other protein markers) and molecular markers (based on DNA-DNA hybridization (Xu, 2010).

DNA markers have developed into many systems based on different polymorphism detecting techniques or methods (southern blotting - nuclear acid hybridization, PCR - polymerase chain reaction and DNA sequencing), such as RFLP, AFLP, RAPD, SSR and SNP (Farokhzadehet al., 2014).DNA marker technology refers to the application of DNA based markers in breeding programs to improve the selection efficiency.However, traditional breeding involves selection of individual plants or animals based on visible or measurable traits. By examining the DNA of an organism, scientists can use molecular markers to select plants or animals that possess a desirable gene, even in the absence of a visible trait. Thus, modern breeding is more precise and efficient. Another use of molecular markers is to identify undesirable genes that can be eliminated in the future generations. However, conventional rice breeding approaches identified improved rice cultivars for thousands of years. But, the progress is slow, due to the time consuming process, the quantitative nature of most agronomic traits and difficulties for genotypes selection (Wang et al., 2007).

In rice, many PCR based markers like randomly amplified polymorphic DNAs (RAPDs), amplified fragment length polymorphisms (AFLPs), inter-simple sequence repeats (ISSRs) and simple sequence repeats (SSRs) are being used. Among the PCR based DNA markers, microsatellites or simple sequence repeats (SSRs) are highly preferred for gene tagging and mapping efforts due to the high level of polymorphism content and versatility and are preferred due to their reproducibility and amenability for automation. More than twenty thousands of SSR markers have been developed in rice so far and their chromosomal location and polymorphism levels have been determined. Due to these reasons, SSRs is the best marker for rice improvement in MAS application (McCouchet al., 2002).Recently, a special class of markers called single nucleotide polymorphisms (SNPs) is gained predominance in those crop species like rice, whose genomes have been sequenced. A single-nucleotide 
polymorphism (SNP, pronounced as snip) is a DNA sequence variation occurring when a single nucleotide A, T, $\mathrm{C}$, or $\mathrm{G}$ in the genome differs between members of a species or paired chromosomes in an individual.

Over the last decades, researchers have developed and applied marker assisted selection (MAS) and quantitative trait locus (QTL) analysis techniques for rice breeding. These approaches promote new germplasm identification and new elite cultivar establishment (Wang et al., 2007). A major QTL designed "Saltol" was mapped on chromosome 1 using a population generated from a cross between the sensitive variety IR29 and a tolerant landrace, Pokkali. This QTL accounts for more than $70 \%$ of the variation in salt uptake in this population and marker assisted backcrossing is being used to incorporate this QTL into popular varieties sensitive to salt stress(Lafitte et al.,2004).

Salt tolerance is a complex trait, so the QTLs related with salt tolerance have a significant role in understanding the stress-response and generating stress-tolerant plants (Gorantla et al., 2005). There are many methods for identifying gene/QTLs such as traditional map-based cloning, new approaches like microarray based transcriptional profiling of differential gene expression or combination of genetic mapping and expression profiling. Analysis of a series of backcross lines and near-isogenic lines developed to better characterize the effect of the Saltol locus revealed that Saltol mainly acted to control shoot $\mathrm{Na}^{+} / \mathrm{K}^{+}$homeostasis(Thomson et al., 2010).Marker assisted selection (MAS) has been seen as a means of improving the speed and efficiency of breeding programs because it is growth stage independent, is unaffected by environment, has no dominance effect and efficient to use in early generations. Marker assisted backcrossing (MABC) is also a useful method for introgression or substitution of a target gene/QTL from salt tolerant parent to recipient by applying molecular markers. The drawbacks in using marker assisted selection is "linkage drag" of undesirable traits due to the large size of regions of chromosome identified by QTL and the fact that environment and genetic background has a significant influence on the QTL (Flowers, 2004). In general, DNA MAS has been seen as a means of improving the speed and efficiency of rice breeding programs because it is growth stage independent, non-environmental effect; no dominance effect and efficient to use in early generations. It is more efficient, effective and reliable than phenotypic selection. Furthermore, MAS can be shortenvarietal development time significantly, so, it is more cost effective than selection through conventional breeding.

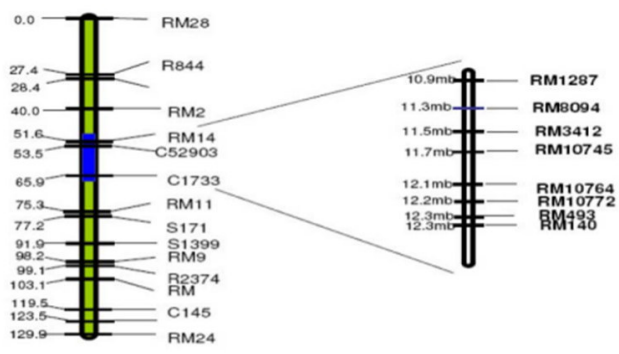

Fig: Saltol segment on chromosome 1 of rice

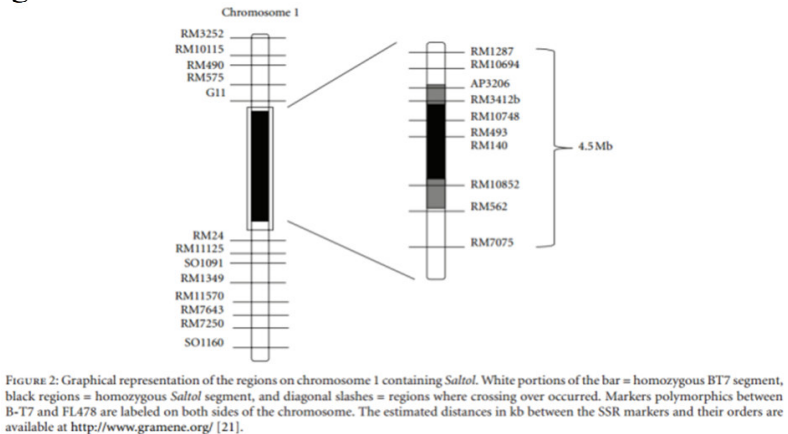

Fig.3.Graphical representation of marker assisted selection for salinity tolerance rice Saltol segment on chromosome 1 of rice. (Adapted from Amaranatha et al, 2014)

\subsection{Genetic engineering approach}

Plant breeding for salt tolerance is not much successful due to reproductive barrier and involvement of undesirable traits transfer. So, to avoid this problem, genetic engineering strategy is more preferred which only deals with the specific gene(s) transferred. Plants try to cope with salinity by inducing various metabolic changes through production of osmolytes, anti oxidative enzymes and up regulating various genes involved in stress response for ion transporters, ion channels, transcriptional factors and various signaling pathway components.

There are a number of gene(s) responsible for salinity tolerancewhich can be transferred to target plants through genetic engineering. When plants haveexposedto stress conditions, metabolic shifts occur and result in changes in the levels of a various cellular metabolites. Such modifications in response to abiotic stress appear to be associated with the enhanced ability to tolerate such stressful conditions(Guy, 1990).

Genetic modification has become a powerful tool in plant breeding program since it allows the introduction of gene(s) controlling traits without affecting the desirable characteristics of an elite genotype. The advent of an efficient Agro-bacterium-mediated transformation method for rice displays great potential from the genetic improvement of the plant. Currently, genetic engineering for salinity tolerance in plants has focused on genes that encode compatible organic solutes, antioxidants, ion transport, heat-shock and late embryogenesis abundant proteins, programmed cell death, signal transduction and transcription factor (figure1). Generally, all of the known mechanisms have been used for rice to cope with salinity through genetic engineering programs to develop salinity tolerance rice varieties (Bhatnagar-Mathur, 2008). 


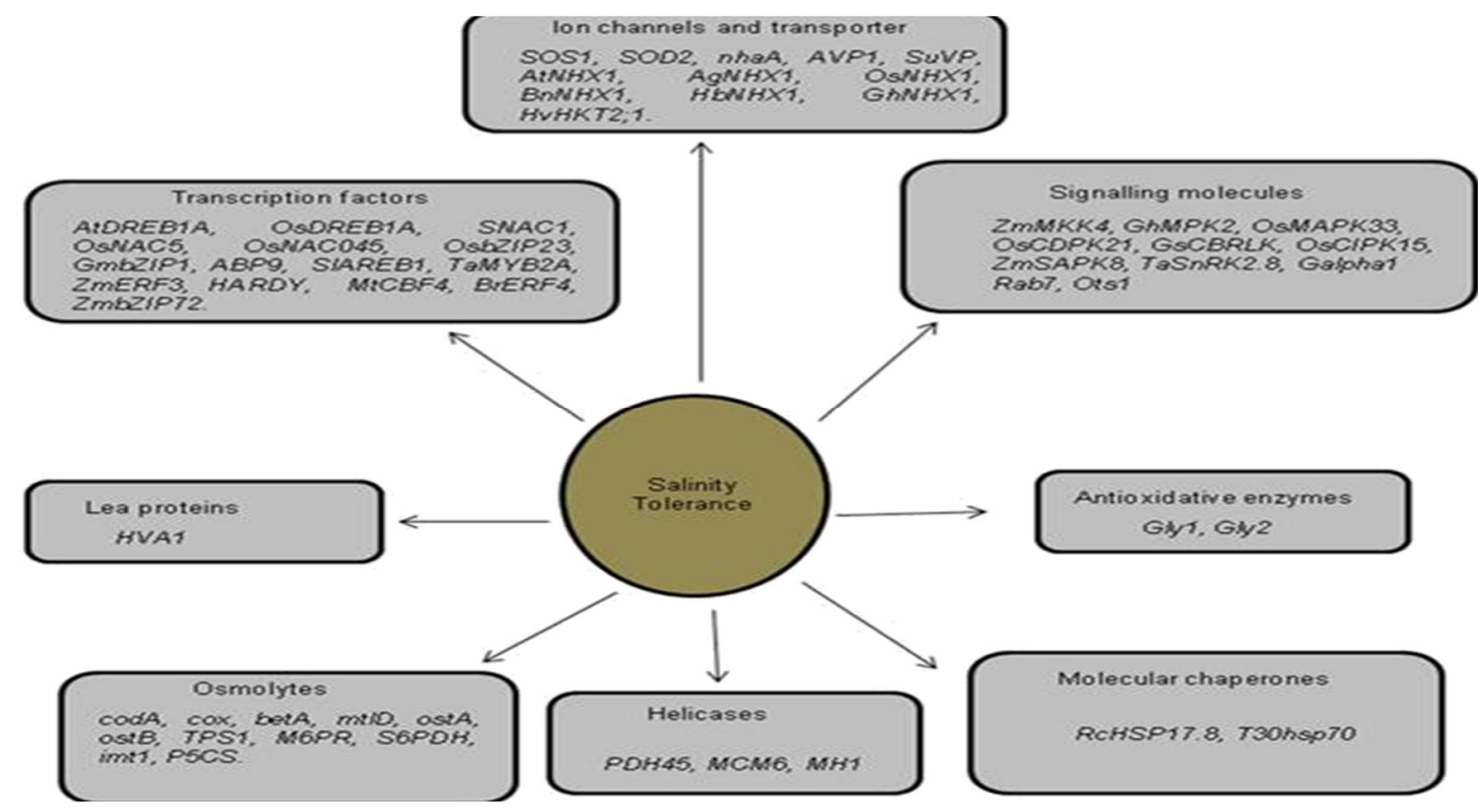

Fig4.Genes coding for different transcription factors, lea proteins, osmolytes, helicases, molecular chaperones, antioxidative enzymes, signalling molecules, ion channels and transporter which are known to impart salinity tolerance to different plants when over expressed (Satpalturan et al., 2012).

The development of salt-tolerant varieties by transgenic way needs more investigation. Transgenic rice varieties for salinity tolerance have not been yet commercialized. To date, transgenic salt tolerant variety was not reached at farmers' field. There are two major constraints that may hinder the success of genetic engineering approach. Firstly, genes were tested for salinity tolerance rice variety development. But, the major response to salinity stress has not yet been confirmed. Currently, the genetic engineering approach for salinity stress tolerance for rice has been transformed single genes in one of the four categories of salt stress response way (i.e., osmoprotectant, antioxidants, ion transporter or programmed cell death)( Sahi et al.,2006).

The response to salinity stress of Pokkali, the natural salt tolerant rice variety, showed that this variety may employ several strategies to cope with salt stress such as transient uptake $\mathrm{Na}^{+}$into cytoplasm and fast extrusion $\mathrm{Na}^{+}$into vacuoles and increase activities of scavenging enzyme such as catalase (CAT) and enhanced levels of antioxidants like ascorbate (ASC) and glutathione (GSH) during salt stress (Vaidyanathanet al., 2003).In addition, there was a weak link between tolerance to salinity stress at seedling and reproductive stages in some genotypes within the species Oryzasaltiva L., which also makes it difficult to ensure that a single gene can strongly enhance salt tolerance in transgenic rice for the whole life cycle. Therefore, it would be worth trying to introgress a locus consisting of genes from different salt response categories into rice for salt tolerant.

The other constraint of genetic engineering approach for salinity stress tolerance in rice is gene silencing. Despite significant scientific and technical advances in gene expression systems and plant transformation technologies, many transgenic plants do not display the expected transgene expression. Epigenetic effects and gene silencing have large influences on gene expression either by transcriptional gene silencing (TGS) or posttranscriptional gene silencing (PTGS). Unfortunately, gene silencing is notoriously unpredictable and represents a significant bottleneck to the success of transgenic systems.

Gene silencing can be triggered by the presence of foreign genes or additional copies of endogenous genes; interestingly, it has also been observed against endogenous genes in non-transgenic plants (Wang and Waterhouse,2000).To overcome transgene silencing, researchers have developed a range of strategies including extra chromosomalepisomal expression, artificial chromosomes, incorporation of introns into transgene coding regions and expression of viral silencing suppressors. Over the last three decades, significant progress has been made towards the mechanisms underpinning gene silencing and the advent of transgenic has significantly accelerated this progress. The emerging technologies of genome editing allow scientists to control the transformation process to either be integration free or at least direct the integration location. This control will no doubt lead to further discoveries and possibly lead to new platforms that alleviate gene silencing to increase the stability of transgene expression in rice.

\subsection{Breeding progress for salt tolerance in Ethiopia}

Salt tolerance varieties not yet released in Ethiopia. But, screening of rice genotypes for salinity tolerance was 
started at Werer Agricultural research Center with collaboration of Bahirdar University food and nutrition laboratory of which has shown a significant variable response between genotypes for salinity stress (Beakaleet al., 2016)(Table2).

Table-2.Physical characteristics of the rice genotypes at Bahirdar University food and nutrition laboratory Table 2. Physical characteristics of the 15 rice genotypes.

\begin{tabular}{|c|c|c|c|c|c|c|c|c|}
\hline \multirow{3}{*}{ Genotype } & \multicolumn{8}{|c|}{ Physical characteristics } \\
\hline & $\mathbf{K L}$ & KB & KT & & TKW & BD & AR & $\mathrm{CH}$ \\
\hline & $(\mathrm{mm})$ & $(\mathrm{mm})$ & $(\mathrm{mm})$ & LBR & (g) & $(\mathrm{kg} / \mathrm{hl})$ & (i) & $(\%)$ \\
\hline AT 401 & $8.14^{a b}$ & $2.73^{\mathrm{bod}}$ & $1.98^{\mathrm{bc}}$ & $2.98^{\mathrm{bC}}$ & $24.00^{b}$ & $59.23^{h}$ & $42.33^{a}$ & $14.54^{t}$ \\
\hline IR 29 & $7.75^{\mathrm{bc}}$ & $2.47^{\mathrm{h}}$ & $1.90^{\circ d}$ & $3.14^{b}$ & $21.00^{\mathrm{e}}$ & $57.69^{i}$ & $38.33^{c}$ & $58.17^{\mathrm{a}}$ \\
\hline IR 55179 & $7.52^{\text {cde }}$ & $2.84^{\mathrm{b}}$ & $2.14^{\mathrm{a}}$ & $2.65 d^{\text {etg }}$ & $24.67^{\mathrm{a}}$ & $62.41^{a}$ & $39.67^{b}$ & $18.17^{d}$ \\
\hline IR 59418 & $6.95^{\mathrm{fg}}$ & $2.78 b^{c}$ & $1.88^{\text {odet }}$ & $2.50^{\mathrm{fg}}$ & $18.17^{9}$ & $61.63^{b}$ & $36.67^{\text {de }}$ & $12.26^{9}$ \\
\hline IR 66946 & $8.07^{a b}$ & $2.71^{\text {bode }}$ & $1.91^{\text {cd }}$ & $2.98^{\mathrm{bc}}$ & $25.00^{\mathrm{a}}$ & $56.63^{j}$ & $34.67^{g h}$ & $12.46^{9}$ \\
\hline IR 70023 & $7.29^{\text {def }}$ & $2.57^{\text {efgh }}$ & $1.88^{\text {odet }}$ & $2.84^{\text {od }}$ & $25.02^{\mathrm{a}}$ & $60.40^{\text {de }}$ & $34.00^{\mathrm{hi}}$ & $5.63^{\prime}$ \\
\hline IR 71810 & $7.42^{\text {ode }}$ & $2.73^{\text {bod }}$ & $1.77^{t}$ & $2.71^{\text {de }}$ & $22.00^{d}$ & $61.36^{b c}$ & $37.00^{d}$ & $16.36^{\mathrm{e}}$ \\
\hline IR 71889 & $6.90^{f g}$ & $2.54^{\operatorname{tgn}}$ & $1.80^{\operatorname{det}}$ & $2.72^{\text {de }}$ & $18.00^{9}$ & $59.09^{h}$ & $36.67^{\text {de }}$ & $12.64^{9}$ \\
\hline IR 71901 & $7.46^{\text {ode }}$ & $3.05^{\mathrm{a}}$ & $2.03^{a b}$ & $2.45^{9}$ & $22.00^{d}$ & $60.13^{\text {ef }}$ & $42.67^{a}$ & $28.63^{b}$ \\
\hline IR 71902 & $7.19^{\text {efg }}$ & $2.79^{b c}$ & $1.95^{\mathrm{bc}}$ & $2.58^{\text {efg }}$ & $23.00^{c}$ & $59.79^{f g}$ & $36.00^{\text {et }}$ & $15.91^{\mathrm{e}}$ \\
\hline IR 71991 & $7.39^{\text {ode }}$ & $2.76^{\mathrm{bc}}$ & $1.90^{\text {cde }}$ & $2.68^{\operatorname{det}}$ & $23.00^{c}$ & $59.27^{g h}$ & $33.33^{i}$ & $11.27^{\mathrm{h}}$ \\
\hline IR 72048 & $7.71^{\text {bod }}$ & $2.81^{b}$ & $1.78^{\mathrm{et}}$ & $2.74^{\text {de }}$ & $19.00^{t}$ & $56.45^{j}$ & $31.67^{i}$ & $11.91^{\text {gh }}$ \\
\hline IR 72593 & $6.84^{9}$ & $2.61^{\operatorname{detg}}$ & $1.80^{\text {det }}$ & $2.63^{\text {etg }}$ & $19.00^{t}$ & $60.86^{\text {cd }}$ & $27.67^{k}$ & $27.55^{c}$ \\
\hline IR 73055 & $8.30^{a}$ & $2.42^{h}$ & $1.97^{\mathrm{bc}}$ & $3.44^{\mathrm{a}}$ & $24.00^{b}$ & $59.19^{h}$ & $35.33^{19}$ & $12.18^{9}$ \\
\hline NERICA4 & $8.11^{a b}$ & $2.65^{\text {odet }}$ & $1.98^{\mathrm{bc}}$ & $3.06^{b}$ & $25.00^{a}$ & $59.29^{\text {gh }}$ & $36.00^{\mathrm{et}}$ & $27.26^{c}$ \\
\hline Mean & 7.54 & 2.70 & 1.91 & 2.81 & 21.79 & 59.56 & 36.13 & 19.00 \\
\hline $\operatorname{LSD}(0.05)$ & 0.43 & 0.15 & 0.12 & 0.21 & 0.46 & 0.53 & 0.82 & 0.79 \\
\hline $\mathrm{CV}(0.05)$ & 3.42 & 3.37 & 4.66 & 6.33 & 1.27 & 0.54 & 1.36 & 2.51 \\
\hline
\end{tabular}

Where; $\mathrm{KL}=$ kernel length, $\mathrm{GB}=$ kernel breadth, $\mathrm{KT}=$ kernel thickness, $\mathrm{LBR}=$ length-to-breadth ratio, $\mathrm{TKW}=$ thousand kernel, weight, $\mathrm{BD}=$ bulk density, $\mathrm{AR}=$ angle of repose, $\mathrm{CH}=$ chalkiness respectively, $\mathrm{CV}=$ coefficient of variation NERICA: New Rice for Africa that is, Means within a column with the same superscripts are not significantly different at $5 \%$.

Table 3. Proximate composition of 15 salt tolerant rice genotypes.

\begin{tabular}{|c|c|c|c|c|c|}
\hline \multirow{2}{*}{ Genotypes } & \multicolumn{5}{|c|}{ Nutrient analysis } \\
\hline & Protein (\%) & Fat $(\%)$ & Fiber (\%) & $\mathrm{CHO}(\%)$ & Energy (Kcal) \\
\hline AT 401 & $10.17^{b}$ & $2.35^{h}$ & $6.07^{\mathrm{a}}$ & $77.56^{k}$ & $372.07^{\prime}$ \\
\hline IR 29 & $5.42^{\circ}$ & $4.33^{\mathrm{a}}$ & $3.04^{\mathrm{h}}$ & $81.26^{e}$ & $385.66^{a}$ \\
\hline IR 55179 & $6.06^{n}$ & $2.17^{i}$ & $5.43^{d}$ & $82.43^{b}$ & $373.49^{k}$ \\
\hline IR 59418 & $9.27^{e}$ & $2.34^{\mathrm{h}}$ & $5.97^{\mathrm{ab}}$ & $79.26^{h}$ & $375.17^{i}$ \\
\hline IR 66946 & $8.24^{h}$ & $2.33^{h}$ & $4.74^{\mathrm{e}}$ & $80.35^{t}$ & $375.34^{\mathrm{hi}}$ \\
\hline IR 70023 & $10.56^{\mathrm{a}}$ & $2.17^{i}$ & $5.80^{b c}$ & $78.71^{i}$ & $376.58^{9}$ \\
\hline IR 71810 & $8.48^{9}$ & $2.49^{9}$ & $3.88^{f}$ & $80.29^{t}$ & $377.53^{t}$ \\
\hline IR 71889 & $9.17^{f}$ & $2.66^{d}$ & $5.82^{b c}$ & $79.51^{9}$ & $378.66^{d}$ \\
\hline IR 71901 & $9.90^{c}$ & $2.58^{e}$ & $6.15^{\mathrm{a}}$ & $77.88^{j}$ & $374.35^{j}$ \\
\hline IR 71902 & $7.28^{k}$ & $2.16^{i}$ & $3.66^{\text {tg }}$ & $82.28^{b}$ & $377.67^{\mathrm{ef}}$ \\
\hline IR 71991 & $7.75^{j}$ & $1.95^{\mathrm{j}}$ & $2.95^{h}$ & $81.83^{\text {cd }}$ & $375.88^{g h}$ \\
\hline IR 72048 & $7.95^{i}$ & $1.81^{k}$ & $3.71^{19}$ & $81.93^{c}$ & $375.81^{\mathrm{ni}}$ \\
\hline IR 72593 & $6.35^{\mathrm{m}}$ & $2.74^{b}$ & $2.90^{h}$ & $82.94^{\mathrm{a}}$ & $381.83^{b}$ \\
\hline IR 73055 & $9.52^{d}$ & $2.54^{t}$ & $5.71^{c}$ & $79.36^{g h}$ & $378.35^{\text {de }}$ \\
\hline NERICA4 & $7.18^{\prime}$ & $2.69^{c}$ & $3.61^{9}$ & $81.68^{d}$ & $379.65^{\circ}$ \\
\hline Mean & 8.22 & 2.49 & 4.63 & 80.49 & 377.22 \\
\hline LSD (0.05) & 0.24 & 0.18 & 0.71 & 0.62 & 0.63 \\
\hline $\mathrm{CV}(0.05)$ & 0.25 & 0.50 & 3.17 & 0.13 & 0.11 \\
\hline
\end{tabular}

Where; $\mathrm{CHO}=$ carbohydrate content; $\mathrm{CV}=$ coefficient of variation, NERICA: New Rice for Africa; i.e. means within a column with the same superscripts are not significantly different at $5 \%$.

Source: (Beakale et al., 2016)

The result showed number of grains decreased with increased salinity and this effect was more pronounced in genotype IR61247-3B-8-2-1 (G3). Genotype IR68144-2B-2-2-3-3 (G9) followed by IR68144-2b-2-2-3-2 (G8) and IR66946-3R-176-1-1 (G15) gave significantly higher 100-grain weight than sensitive genotype IR29 (G14) even at $8 \mathrm{dSm}^{1}$. Grain weight is largely determined by the duration and rate of grain filling. Therefore, environmental stresses that tend to shorten the grain filling period that significantly reduce final grain weight

\section{Conclusions and Recommendation}

Rice is the staple food crop for more than one half of the world's population and is grown widely in 114 countries across the world. Hence, improvement of rice production highly required for every corner of the world. Wild rice is a good option to be used as a genetic resource and a candidate selection at salt-affected flooding areas forsalinity tolerance and high grain quality. The three major breeding approaches next to primary activities for salt tolerance varietal development are conventional breeding, marker assisted selection and genetic engineering. Modern breeding approaches have a greater advantage than conventional for salt tolerance. Because, markers can identify 
a desirable gene, even in the absence of a visible trait; breeding result is more precise and efficient and identify undesirable genes that can be eliminated in future generations

In rice, markers like randomly amplified polymorphic DNAs (RAPDs), amplified fragment length polymorphisms (AFLPs), inter-simple sequence repeats (ISSRs) and simple sequence repeats (SSRs) have been used. Among these DNA markers, microsatellites or simple sequence repeats (SSRs) is highly preferable for gene tagging and mapping efforts. The development of a salt-tolerant cultivar by transgenic way needs more investigation. To date, transgenic salt tolerant variety has not yet reached at farmers' field. One of pre required rice variety development for salt tolerance is wide variability in the available germplasm. In Ethiopia a little beat was done to identify rice genotypes adaptable to adverse saline soil conditions. From here on, more research findings highly crucial for the development of salinity tolerant rice varieties in the country. Therefore, it is a good opportunity for rice breeders to develop salt tolerant high yielding varieties in Ethiopia.

\section{Reference}

African biotechnology stakeholder's forum (ABSF).2010. Success Stories in Crop Improvement in Africa: The Case of Rice in Sub-Saharan Africa

Bhatnagar-Mathur P., Vadez V. and Sharma K.K. 2008. Transgenic approaches for abiotic stress tolerance in plants: Retrospect and prospects. Plant Cell Rep. 27:411-424.

Boje-Klein G. 1986. Problem soils as potential areas for adverse soil-tolerant rice varieties in South and Southeast Asia. IRRI Research Paper Series 119: pp 53.

Calpe C. 2006.Rice international commodity profile.Food and Agriculture Organization of the United Nations. Markets and Trade Division.pp 23

Das A., Gosal S.S., Sidhu, J.S. and Dhaliwal H.S. 2000.Induction of mutations for heat tolerance in potato by using in vitroculture and radiation.Euphytica, $120: 205-209$.

FAO.2013.Cereal Supply and Demand Brief(http:// www.fao.org/worldfoodsituation / wfs-home/csdb/en/)

Farokhzadeh S., AliFakheri B. 2014. Marker-assisted Selection for Disease Resistance: Applications in Breeding.Faculty of Agriculture, Zabol University. Intl J Agri Crop Sci. 7 :1392-1405

Flowers T.J. 2004.Improving crop salt tolerance. J. Exp. Bot.,55:307-319.

Goff S. A., Ricke D., Lan T. H., Presting G., Wang R., Dunn M., Glazebrook J., Sessions A., Hadley D., Hutchison D., Martin C., and Briggs S. 2002. A draft sequence of the rice genome (Oryza sativa L. ssp. japonica). Science, $296: 92-100$

Gorantla M.; Babu P.R.; Reddy V.B.L.; Feltus F.A.; Paterson A.H.and Reddy A.R. 2005. Functional genomics of drought stress response in rice: Transcript mapping of annotated unigenes of an indica rice (Oryza sativa $\mathrm{L}$. cv. Nagina 22). Curr. Sci., 89: 496-514.

Guy CL .1990. Cold acclimation and freezing stress tolerance: Role of protein metabolism. Annu Rev Plant Physiol Plant MolBiol 41:187-223

http://www.nodai.ac.jp/cip/iss/ , 2015

Khatun S., Rizzo C.A. and Flowers T.J. 1995. Genotypic variation in the effect of salinity on fertility in rice. Plant Soil, 173: 239-250.

Khatun, S., Rizzo C.A. and Flowers T.J. 1995. Genotypic variation in the effect of salinity on fertility in rice. Plant Soil, 173: 239-250

Lafitte H.R.; Ismail A.M. and Bennett J.2004. Abiotic stress tolerance in rice for asia: Progress and future. In Proceedings of the 4th International Crop Science Congress, Brisbane, Australia

Lee I.S., Kim D.S., Lee S.J., Song H.S., Lim Y.P. and Lee Y.I. 2003.Selection and characterizations of radiationinduced salinity-tolerant lines in rice. Breed. Sci.53:313-318.

McCouch SR, Chen X, Panaud U, Temnykh S, Xu. Y, Cho YG, Huang N, Ishii T and Blair M. 1997.Microsatellite marker development, mapping and applications in rice genetics and breeding.Plant MolBiol35: 89-99.

Miller G.A.D.; Suzuki N.; Ciftci-Yilmaz S. and Mittler R.O.N. 2010 Reactive oxygen species homeostasis and signalling during drought and salinity stresses. Plant Cell Environ. 33:453-467

Mishra B., Singh R. K., and Bhattacharya R. K. 1992. CSR10, a newly released dwarf rice for salt affected soils. IRRN, 17(1):19.

Mohanty S., smann Nelson A., Moya P and Jagadish S.V.K. 2013. Rice and climate change: significance for food security and vulnerability.

PROGRAM FOR BIOsafetysytems and U.S. Agency for International Development, Agricultural Biotechnology Support Project II, and the Program for Biosafety Systems and (PBS, ABSP11).2004.Agricultural Biotechnology.

Sahi C.; Singh A.; Kumar K.; Blumwald E. and Grover A. 2006. Salt stress response in rice: Genetics, molecular biology, and comparative genomics. Funct.Integr.Genom. 6:263-284.

Singh R. K., and Mishra B. 1997. Stable genotypes of rice for sodicsoils.Ind. J. Genet. 57(4): 431-438.

Singh R. K., and Mishra, B. (1997).Stable genotypes of rice for sodicsoils.Ind. J. Genet. 57(4): 431-438. 
Sinha T. S. 1997. Evaluation and breeding of Indian mustard (B. juncea) for salt tolerance. In: Annual Report, CSSRI, Karnal, 1996-97. pp 52-53.

Thomson M.J.; de Ocampo M.; Egdane J.; Rahman M.A.; Sajise A.G.; Adorada D.L.; and Ismail A.M. 2010.Characterizing the saltol quantitative trait locus for salinity tolerance in rice. 3:148-160.

Vaidyanathan H.; Sivakumar P.; Chakrabarty R.; and Thomas G. 2003.Scavenging of reactive oxygen species in nacl-stressed rice (Oryza sativa L.) - Differential response in salt-tolerant and sensitive varieties. Plant Sci. 165:1411-1418.

Wang M.B. and Waterhouse P.M. 2000. High-efficiency silencing of a beta-glucuronidase gene in rice is correlated with repetitive transgene structure but is independent of DNA methylation. Plant Mol. Biol., 43:6782.

Wang Y.M. Chen and J. Li., Rice. Pua and Davey M.R. M.R.2007.Biotechnology in Agriculture and Forestry. Vol. 59Transgenic Crops IV. Springer-Verlag Berlin Heidelberg pp35-47.

Winicov I. 1998. New Molecular approaches to improving salt tolerance in crop plants.Ann. Bot., 82 : 703-710.

$\mathrm{Xu}$, Y. 2010. Molecular plant breeding. CAB International.

Zeng L., Poss J.A., Wilson C.,Draz A.S.E., Gregorio G.B. and Grieve C.M. 2003. Evaluation of salt tolerance in rice genotypes by physiological characters. Euphytica,129:281-292.

Zeng L., Shannon M.C. and Lesch S.M. 2001. Timing of salinity stress affects rice growth and yield components. Agric. Water Manag., 48 : 191-206.

Zhu J.K. 2000.Genetic analysis of plant salt tolerance using Arabidopsis thaliana. Plant Physiol., 124 : 941-948.

Zibaee A. 2013. Rice: Importance and Future. J Rice Res 1: e102. doi:10.4172/jrr.1000e102 